\title{
Mice overexpressing wild-type human alpha-synuclein display alterations in colonic myenteric ganglia and defecation
}

\author{
L. WANG ${ }^{*}$, I. MAGEN ${ }^{+}$, P-Q YUAN ${ }^{*}$, S. R. SUBRAMANIAM ${ }^{+}$, F. RICHTER ${ }^{+}$, M-F CHESSELET $^{+}$, \\ and Y. TACHÉ \\ "CURE: Digestive Diseases Research Center and Center for Neurobiology of Stress, Department \\ of Medicine, Division of Digestive Diseases, David Geffen School of Medicine, University of \\ California Los Angeles and Veteran Affairs Greater Los Angeles Healthcare System, Los \\ Angeles, USA
}

+Department of Neurology, David Geffen School of Medicine, University of California Los Angeles, Los Angeles, California, USA

\begin{abstract}
Background-Prevalent non-motor symptoms of Parkinson's disease (PD) include gastrointestinal motor impairments and advanced stage PD displays pathological aggregates of asynuclein in colonic enteric neurons. We previously showed that 12 months old mice overexpressing human wild type a-synuclein under the Thy 1 promoter (Thy 1-aSyn) displayed colonic motor dysfunction. We investigated functional gut alterations at earlier ages and histological correlates.
\end{abstract}

Methods-Defecation, gastric emptying (GE), and immunostaining for a-synuclein, peripheral choline acetyltransferase (pChAT), tyrosine hydroxylase $(\mathrm{TH})$, neuronal nitric oxide synthase (nNOS), and vasoactive intestinal peptide (VIP) in distal colon myenteric plexuses were assessed in male Thy1-aSyn compared to littermate wild type (WT) mice.

Key Results-Thy1-aSyn mice aged $2.5-3$ or $7-8$ months old had $81 \%$ and $55 \%$ reduction in fecal pellet output, respectively, to the first $15 \mathrm{~min}$ of exposure to a novel environment. The reduction remained significant in the older group for 2-h, and subsequent refeeding resulted also in a $60 \%$ and $69 \%$ reduction of defecation in the first hour, respectively. Thy 1-aSyn mice (8-10 months) displayed increased a-synuclein in the myenteric plexuses with abundant varicose terminals surrounding pChAT-immunoreactive (ir) neurons, and only a few, nNOS-ir neurons. There were no conspicuous changes in pChAT- and nNOS-ir neurons, or TH- and VIP-ir nerve fibers. Thy1-aSyn mice aged 4-18 months had normal GE.

Conclusions \& Inferences-The occurrence of over-production of pre-synaptic a-synuclein in colonic myenteric ganglia several months before the loss of striatal dopamine may provide an anatomical basis for interference with cholinergic neuronal activation, causing an early impairment in defecation to stimuli.

\section{Keywords}

colon; defecation; gastric emptying; mice; myenteric neurons; pChAT; a-synuclein

Corresponding Author: Lixin Wang, MD, PhD, 11301 Wilshire Blvd., Bldg. 115, Los Angeles, CA 90073, USA, Tel.: 3104783711 ex 41831, Fax: 310268 4963, lixinw@ucla.edu. 


\section{INTRODUCTION}

Parkinson's disease (PD) is characterized by motor symptoms but also includes various nonmotor disturbances, in particular frequent gastrointestinal (GI) dysfunction $(1,2)$ namely constipation and delayed gastric emptying, which predate the onset of motor symptoms such as bradykinesia, rigidity, tremor and postural instability (1-4). In fact, constipation is one of the most prevalent non-motor symptoms of PD (1) and it has been identified as a predictor of developing PD in a retrospective study $(2,3)$.

Alpha-synuclein is associated with both sporadic and familial forms of PD (5). The hallmark of pathological changes in PD is the accumulation of a-synuclein in Lewy bodies and Lewy neurites in neurons of central and peripheral nervous systems (6). Pathological accumulation of a-synuclein is detected in gastric and colonic enteric neurons in post mortem tissues from patients with advanced PD (7-9). These neuroanatomical alterations observed in human patients with PD suggest that enteric a-synuclein accumulation may play a role in the development of the digestive pathology occurring in PD.

So far, there is a paucity of relevant experimental models of GI dysfunction associated with a-synuclein pathology. Lines of transgenic mice expressing mutant form of human asynuclein (either A53T or A30P) under its own promoter present constipation-like colonic disorders and characteristic pathology of a-synuclein (10). However, mutations of $a$ synuclein are responsible for only rare cases of PD (11). A chemical PD model induced by 1-methyl-4-phenyl-1,2,3,6-tetrahydropyridine (MPTP) in mice showed an increase in asynuclein protein in the duodenum but not in the colon (12). We have recently reported that mice overexpressing human wild type a-synuclein under the Thy-1 promoter (Thy1-aSyn) exhibit increased colonic transit time and content compared with wild type (WT) littermates when tested at 12-14 months old (13). However, while the loss of striatal dopamine occurs only after 14 months of age in Thy1-aSyn mice, they express motor and non-motor deficits, such as olfactory impairments, as early as $2-3$ months of age $(14,15)$.

Therefore, in the present study, we investigated whether the onset of colonic motor dysfunction in Thy 1-aSyn mice occurred at earlier ages (2.5-8 months) by testing their colonic responsiveness to a mild novel environment stressor known to increase propulsive colonic motor function in mice (16-18) and postprandial defecation. The locomotor response of Thy1-aSyn mice compared to their WT littermates was also monitored in a novel environment (open field test). To get insight into the underlying neuroanatomical basis of defecation alterations, we examined the distribution of a-synuclein in whole mount preparations of distal colonic myenteric neurons, and its relationship with transmitters known to regulate propulsive colonic motor function. In particular, we identified cholinergic neurons (19) with an antibody against the peripheral form of choline acetyltransferase (pChAT) (20) that we previously reported to provide a powerful tool to visualize cholinergic neurons in the rodent colonic myenteric system $(21,22)$. Other peptides and neurotransmitters including tyrosine hydroxylase $(\mathrm{TH})$, neuronal nitric oxide synthase (nNOS), and vasoactive intestinal peptide (VIP) were also examined. Lastly, we assessed whether the upper gut transit was also altered by determining fasting and postprandial gastric emptying (GE) in Thy1-aSyn mice aged from 4 to 18 months compared to age matched wild-type (WT) mice.

\section{MATERIALS AND METHODS}

\section{Animals}

Thy1-aSyn mice overexpressing human wild-type a-synuclein under the membrane glycoprotein Thy1 promoter were originally generated by the laboratory of E. Masliah 
(UCSD) as previously described (23). They were crossed onto a mixed C57BL/6-DBA/2 (BDF1) background and maintained on this background by mating N5 hemizygous females for the transgene with male WT (24). The experiments were performed in male transgenic mice (2.5-18 months) and their WT littermates. In GE experiments, we additionally used male BDF1 mice (3 months old, Charles River, Wilmington, MA) and Thy1-aSyn mice that were fully backcrossed with C57BL/6 and their WT littermates (5 months old). Mutant or WT mice were housed in groups of 4 or less per cage under controlled conditions of temperature $\left(21-23^{\circ} \mathrm{C}\right)$ and illumination $(6: 00 \mathrm{AM}$ to 6:00 PM) with free access to water and standard rodent diet (Prolab RMH 2500; LabDiet, PMI Nutrition, Brentwood, MO, USA) except otherwise stated. Genotyping of all Thy1-aSyn and WT mice was performed by polymerase chain reaction (PCR) amplification analysis of tail DNA both after birth and at the end of the experiments. Animal care was conducted in accordance with the United States Public Health Service Guide for the Care and Use of Laboratory Animals. Animal experiments were approved by the UCLA and the West Los Angeles Veteran Affairs Committees for Animal Use and Care (protocol number 06015-08).

\section{Fecal pellet output and food intake in response to novel environment}

The novel environment consisted of placing mice singly in a new cage similar to their home cage for a 4-h period except with a grid at the bottom to prevent coprophagy. Different groups of naïve male Thy 1-aSyn mice and WT littermates aged 2.5-3 months or 7-8 months were placed one per cage at 9:00AM for a 2-h period in the light phase with no access to water and food. Fecal pellet output was monitored every $15 \mathrm{~min}$ for the first $\mathrm{h}$ and then at the end of the $2^{\text {nd }} \mathrm{h}$. Thereafter, mice were allowed to pre-weighed chow and water for another $2 \mathrm{~h}$, and fecal pellet output as well as food intake were monitored hourly. In another experiment, different cohorts of 8 months-old Thy1-aSyn mice and WT littermates were placed singly in new cages at $30 \mathrm{~min}$ after the onset of the dark phase (light cycle on-off $11 \mathrm{PM}-11 \mathrm{AM}$ ) for a 1-h period without food and water, and pellet output was monitored every $15 \mathrm{~min}$. The method to monitor food intake was similar to that described previously in mice (25). Pre-weighed standard rodent chow was placed at each time point of food intake measurements. Food intake was determined by calculating the difference between the preweighed standard chow and the weight of chow and spills at the end of each time point. Pellet output and food intake per mouse per time period of monitoring were corrected for body weight (BW) and expressed as number/30 $\mathrm{g} \mathrm{BW}$ and cumulative pellet output reflects the sum of the numbers of pellets for each consecutive period.

\section{Open field test}

Male Thy 1-aSyn and WT mice (4-5 months old) were habituated to the testing room for $1 \mathrm{~h}$ at the beginning of the dark phase. Spontaneous activity in the open field was monitored using an automated system that detected movement with infrared beam breaks (Tru Scan Activity Monitoring System for mice, Coulbourn Instruments, Allentown, PA). Beam break information was collected using Tru Scan V 1.012.00 software. Mice were placed individually in the center of the open field $(25.5 \mathrm{~cm}$ square) and monitored for $15 \mathrm{~min}$. The testing took place within the first $2-4 \mathrm{~h}$ of the dark cycle. The center time was measured as percentage of time spent in the center, out of the total time of each bin which is $5 \mathrm{~min} / \mathrm{bin}$. Distance covered in the horizontal plane and rearings, center time, and center entries were monitored and analyzed for $15 \mathrm{~min}$ in $3 \times 5$ min time bins (modified from our previous study) (26). Correlation was done between number of fecal pellets collected at the end of the 15-min session and each one of the parameters: move time, distance traveled, center time and center entries, and also between the body weight and the above mentioned four parameters. 


\section{Gastric emptying of standard rodent chow or non-nutrient semi-liquid}

All the experiments were performed between 9:00 - 11:00 AM in the light phase. Basal gastric emptying of non nutrient semi-liquid was assessed as described in our previous studies (27). Thy1-aSyn mice (C57BL/6-DBA/2 mixed background, namely BDF-1) and their WT littermates, and WT non-littermate BDF-1 mice (3 to 18 month old as detailed in Table 1) were fasted overnight $(16-18 \mathrm{~h})$ and gavaged with $0.3 \mathrm{ml}$ viscous non-nutrient liquid meal composed of $1.5 \%$ methylcellulose with $0.05 \%$ phenol red, a non-absorbable marker (Sigma-Aldrich Corp, St. Louis, MO). After $30 \mathrm{~min}, 40 \mathrm{~min}$ or $2 \mathrm{~h}$, mice were euthanized by cervical dislocation, and the stomach was removed, homogenized and centrifuged at $3,000 \mathrm{rpm}$ at $4{ }^{\circ} \mathrm{C}$. Gastric emptying was determined by measuring the amount of phenol red in the supernatant with a spectrophotometer (Shimadzu 260, Shimadzu Scientific Instrument, Columbia, MD). One or two WT mice that were euthanized immediately after gavage served as a standard for each determination. The percentage of GE was calculated using the equation: $\%$ emptying $=(1$-absorbance of test sample/absorbance of standard) $\times 100$.

The gastric emptying of solid food was determined as previously described with slight modifications (28). Overnight fasted (16-18 h) Thy 1-aSyn mice (C57BL/6-DBA/2 mixed background) or fully backcrossed with C57BL/6 and their respective WT littermates, and WT non-littermate BDF-1 mice (3-10 month old as detailed in Table 1) were given free access to pre-weighted standard rodent chow and water for $2 \mathrm{~h}$ and then euthanized by cervical dislocation followed by thoracotomy. The abdominal cavity was opened and the stomach removed. The amount of food $(\mathrm{g})$ contained in the stomach was calculated as the difference between the total weight of the stomach with content and the weight of the stomach wall after the content was removed. The solid food ingested by each animal was determined by the difference between the weight of the rodent pellet chow before feeding and the weight of the pellets and spills at the end of the $2 \mathrm{~h}$ feeding period. The percentage of gastric emptying for the $2 \mathrm{~h}$ period was determined according to the equation: $\%$ of gastric emptying $=(1-$ gastric content/food intake $) \times 100$.

\section{Immunohistochemistry for $\alpha$-synuclein and double-labeling in whole mount preparation of colon enteric plexus}

We collected the distal colonic tissues of 8-10 months old Thy1-aSyn mice $(40.0 \pm 2.0 \mathrm{~g})$ and WT littermates $(43.2 \pm 2.2 \mathrm{~g})$ that were euthanized by cervical dislocation and performed whole-mount preparation consisting of the serosa and longitudinal muscle layer with the myenteric plexus attached to its internal side (longitudinal muscle/myenteric plexus, LMMP) as previously described (21).

Free floating distal colon LMMP were treated with or without protease K (Invitrogen, Carlsbad, CA) in $10 \mathrm{mg} / \mathrm{ml}$ phosphate buffered saline (PBS) for $10 \mathrm{~min}$ at room temperature, and then incubated with a monoclonal mouse anti-rat $\alpha$-synuclein- 1 amino acids 15-123 recognizing rat, mouse and human a-synuclein (1:4,000, BD Transduction Laboratories, Cat\# 610787, San Jose, CA) for 2 nights at $4^{\circ} \mathrm{C}$ followed by donkey antimouse IgG conjugated with Alexa Flour ${ }^{\circledR} 594$ (1:500; Invitrogen) for $2 \mathrm{~h}$ at room temperature.

For double labeling, distal colon LMMP were incubated for 2 days at $4^{\circ} \mathrm{C}$ with the same anti-aSyn mentioned above together with rabbit antibodies against either pChAT $(1: 2,000$, Dr. Hiroshi Kimura, Otsu, Japan), TH (1: 1,000, Millipore, AB152, Billerica, MA), nNOS (1:500, AB5380, Millipore), or VIP (1:1,000, CURE ab \# 7913, UCLA). The secondary antibodies were donkey anti-mouse IgG conjugated with Alexa Flour ${ }^{\circledR} 594$ (1:500, 
Invitrogen) and goat anti-rabbit IgG FITC (1:500, Jackson ImmunoResearch, West Grove, $\mathrm{PA})$, and incubation was $2 \mathrm{~h}$ at room temperature.

The whole mounts were examined with fluorescent microscopy and digitally photographed (Axioscop II, Carl Zeiss, Jena, Germany) and confocal microscope (Zeiss LSM 740, Jena, Germany). The varicosities of the aSyn-positive fibers were counted using the particle counts of Image J (version 1.42q, NIH). TH and VIP immunoreactivity was assessed in 9-12 ganglia/distal colon/mouse and quantified using Image $J$ as integrated density per $\mu \mathrm{m}^{2}$. Five - nine ganglia were analyzed from each mouse distal colon LMMP. The pChAT and nNOS immunopositive neurons were counted in 20 ganglia/distal colon/mouse and means were calculated from averages of each mouse as in our previous study (21). The aSyn-ir varicosities adjacent to the pChAT- or nNOS ir neurons were counted in 20 neurons from different myenteric ganglia of distal colon for each mouse. The cell counting and image analyses were performed by an investigator blind to mouse genotype.

\section{Statistical analysis}

Data are expressed as mean \pm SEM and were analyzed by Student $t$-test for comparison between the two genotypes (fecal output and immunoreactivity in the distal colon myenteric plexus), or two-way ANOVA with repeated measures followed by Bonferroni post-hoc comparison for interaction of time course and genotypes using SigmaStat 2.03 (Systat Software, Inc., Point Richmond, CA, USA). One outlier was removed from the Thy1-aSyn group in the move time analysis, and one outlier was removed from the WT group in the analysis of distance traveled, after performing Grubb's test for outliers. The correlation between fecal pellet output and food intake was analyzed by Pearson Correlation test. $P<$ 0.05 was considered significant.

\section{RESULTS}

\section{Young male Thy1-aSyn mice have reduced fecal output in response to novelty stress and postprandially}

Thy 1-aSyn mice aged 2.5-3 months old did not show significant difference in body weight (BW) compared to WT littermates $(30.5 \pm 1.4 \mathrm{~g}, \mathrm{n}=11$ vs. $31.4 \pm 1.2 \mathrm{~g}, \mathrm{n}=9 ; \mathrm{p}>0.05)$. Thy1-aSyn mice placed in a new cage without water and food in the early light phase displayed a significant $81 \%$ and $46 \%$ reduction in the number of pellets expelled during the first 15 min and cumulative 2-h period of novelty exposure, respectively compared to WT littermates (Fig. 1A). Two way ANOVA did not show significant influence in fecal output by genotype $\left(F_{1,72}=3.60, P>0.05\right)$, but did show significant influence by time $\left(F_{4,72}=\right.$ $29.01, P<0.001)$ during the $2 \mathrm{~h}$ novelty test. When the mice were subsequently exposed to food after $2 \mathrm{~h}$ in the novel environment while remaining in the same cage, Thy1-aSyn mice also had a significant 59\% and 57\% lower fecal output than the WT during the 1-h and 2-h periods, respectively. There was no significant difference in food intake during refeeding (Fig. 1B) and no correlation between $1 \mathrm{~h}$ fecal pellets and food intake $\left(r^{2}=0.01, p>0.05\right.$; Fig. 1C).

The same experiments were performed in another cohort of mice7-8 months old (BW: WT $44.3 \pm 1.7 \mathrm{~g}, \mathrm{n}=10$; Thy-1-aSyn $38.3 \pm 1.9 \mathrm{~g}, \mathrm{n}=7, p<0.05$ ). In the first $15 \mathrm{~min}$, the pellet output $/ 30 \mathrm{~g}$ BW was significantly reduced by $55 \%$ in Thy 1 -aSyn mice and throughout the 2 $\mathrm{h}$ novel exposure period compared to WT littermates (Fig. 2A). Two way ANOVA revealed significant influences of genotype $\left(F_{1,124}=8.32, P>0.01\right)$ and time $\left(F_{4-124}=43.79, P<\right.$ 0.001 ) on fecal output during the $2 \mathrm{~h}$ novelty test. When subsequently exposed to food while remaining in the same cage, Thy1-aSyn mice had a significant $70 \%$ and $45 \%$ lower cumulative fecal output compared to WT littermates during 1- and 2-h period of food 
exposure, respectively. Food intake during the 2-h refeeding period was not significantly different between WT and Thy1-aSyn mice (Fig. 2B) and there was no correlation between $1 \mathrm{~h}$ fecal pellets and food intake $\left(r^{2}=0.05, p>0.05\right.$, Fig. $\left.2 \mathrm{C}\right)$.

In another experiment, the 1-h novelty stress was performed in the beginning of the dark phase without food in 8 months old mice (BW: WT $42.8 \pm 1.3 \mathrm{~g}$, Thy1-aSyn $39.0 \pm 2.1 \mathrm{~g} ; p$ $>0.05, \mathrm{n}=5$ /group). Here again, a significant $59 \%$ reduction of fecal pellets in Thy 1 -aSyn mice occurred in the first 15 min of novel environment pellet number $30 \mathrm{~g} \mathrm{BW}$ that remains significant at the $30 \mathrm{~min}$ period but not at later time points compared to WT mice (pellet number/30 g BW: 15 min: $2.5 \pm 0.7$ vs. $6.1 \pm 0.6$; 30 min: $5.8 \pm 0.8$ vs. $8.6 \pm 1.1$ ). Two way ANOVA showed significant influences of genotype $\left(\mathrm{F}_{1,32}=5.7, p<0.05\right)$, time $\left(\mathrm{F}_{3,32}=\right.$ $35.0, p<0.001)$ and genotype $\times$ time $\left(\mathrm{F}_{3,32}=6.5, p=0.001\right)$ on fecal output. There was no difference in $1 \mathrm{~h}$ cumulative fecal output (data not shown).

\section{Open field locomotion}

Male WT (BW: $38.2 \pm 1.7 \mathrm{~g}, \mathrm{n}=12$ ) and Thy1-aSyn (BW: $33.4 \pm 1.14 \mathrm{~g}, \mathrm{n}=11 ; p<0.05$ ) mice (4-5 months old) were naïve to the open field. Time spent in locomotion was significantly higher in Thy 1 -aSyn mice than in WT mice $\left(\mathrm{t}_{20}=4.23, p<0.001\right.$; Fig. 3A) during a 15 min monitoring. Similarly, Thy $1-$ aSyn mice traveled significantly greater distances than WT mice $\left(\mathrm{t}_{20}=4.04, p<0.001 ;\right.$ Fig. 3B). Thy 1 -aSyn mice had more center entries compare to WT $\left(\mathrm{t}_{21}=3.1, p=0.005\right.$; Fig. 3C) and spent more time in the center $\left(\mathrm{t}_{21}\right.$ $=3.28, p=0.004 ;$ Fig. 3D). At the same time, Thy $1-$ aSyn mice had fewer fecal output pellets then WT mice $\left(\mathrm{t}_{21}=2.27 . p=0.03\right.$; Fig. 3E), which were negatively correlated to move time $\left(r^{2}=0.47, p<0.05\right)$ and center time $\left(r^{2}=-0.45, p<0.05\right)$, but not to distance traveled $\left(r^{2}=-0.42, \mathrm{p}>0.05\right)$ or center entries $\left(r^{2}=-0.39, p>0.05\right)$. Body weight was not correlated with either locomotion time or distance traveled $(p>0.05)$, suggesting that the Thy1-aSyn mice were not hyperactive due to a lower body weight.

\section{Immunohistochemistry of distal colonic myenteric neurons in Thy1-aSyn mice}

Immunoreactivity for a-synuclein, using an antibody against rat synuclein-1 aa 15-123 recognizing both mouse and human a-synuclein, was detected in the distal colon myenteric plexuses in WT (Fig. 4A) and much more prominently in Thy1-aSyn mice (8-10 months old, Fig. 4B) without protease $\mathrm{K}$ treatment. The staining was mainly localized to varicosities of neuronal fibers and occasionally a couple of positive neurons were observed in both genotypes (data not shown and Figs. 5A, 6B, D). Image analysis of the labeled varicosities as particle counts showed a significant 3-fold higher density of a-synuclein-positive fibers in Thy1-aSyn mice than in their WT littermates in distal colonic myenteric ganglia (Table 2). No a-synuclein immunoreactivity was detected after protease $K$ treatment (data not shown).

Immunoreactivity for TH in WT (Fig. 5A) and Thy1-aSyn mice (Fig. 5B), and VIP in WT (Fig. 5C) and Thy1-aSyn mice (Fig. 5D), was abundant in neuronal fibers of mouse distal colon myenteric plexuses and occasionally observed in single neuronal somas in some ganglia of both genotypes (Fig. 5A). There were no differences between Thy1-aSyn and WT mice in the density of TH or VIP-ir neuronal fibers (Table 2). Few double-labeled neuronal fibers with TH-ir or VIP-ir and a-synuclein were found (data not shown).

Numerous myenteric neurons of the distal colon expressed pChAT in both WT and Thy1aSyn mice (Fig. 6A, B). These pChAT positive cells showed morphological features of Dogiel types I (small cell bodies and short dendrites) and II (round-oval neurons with smooth surfaces and prominent processes) (19) as we previously described (21). Myenteric neurons labeled by nNOS were of large and medium sizes and fewer than pChAT neurons in 
ganglia of both WT and Thy1-aSyn mice (Fig. 6C, D). The numbers of pChAT-ir and nNOS-ir neurons were not different between WT and Thy1-aSyn mice (Table 2). Double immunolabeling revealed a few aSyn-positive varicose terminals formed juxtapositions to the pChAT-ir and nNOS-ir neurons in WT mice (Fig. 6A, C). However, in Thy1-aSyn mice, abundant aSyn-positive varicose terminals were adjacent to the pChAT-ir (Fig. 6B), while only a few surrounded nNOS-ir neurons (Fig. 6D), which was confirmed by semiquantitative analysis $(7.4 \pm 1.2$ vs. $1.0 \pm 0.4$ juxtapositions of aSyn-positive varicosities/ neuron, respectively $p<0.001)$. Few double-labeled neuronal somas and fibers with pChAT-ir or nNOS-ir and a-synuclein were found in both genotypes (data not shown).

\section{Thy1-aSyn mice of different ages have no alteration in gastric emptying}

Table 1 summarized results of gastric emptying in WT BDF1 mice aged 3 months, Thy $1-$ aSyn mice with mixed C57BL/6-DBA/2 background (BDF1) aged from 4 to 18 months old compared with their respective WT littermates, and Thy1-aSyn mice backcrossed with C57BL/6 and their WT littermates (5 months old). There was no alteration in gastric emptying of either solid chow meal or non nutrient viscous solution between Thy1-aSyn mice and corresponding WT littermates in any of the age groups examined.

Thy1-aSyn mice aged 9 to 18 month old displayed significant reductions in body weight compared to their same age WT littermates whereas no differences were present at a younger age (5 months old).

\section{DISCUSSION}

The present study showed that Thy1-aSyn mice aged $2.5-8$ months display reduced defecation in response to a novel environment or postprandially. These deficits occur earlier than the previously established loss of striatal dopamine which takes place at 14 months in these mice (14). The constipation-like phenotype was associated with a robust expression of a-synuclein in nerve fibers in the distal colonic myenteric ganglia that appear in close apposition to cholinergic neurons. In contrast, gastric emptying of standard rodent chow or non-nutrient semi-liquid was not altered in Thy1-aSyn mice at any of the ages examined (418 months).

Thy 1-a-Syn mice $2.5-3$ months old subjected to a mild stress, i.e. exposed singly to a novel environment during the light phase for 2-h without food and water, displayed a significant reduction in fecal output compared with WT littermates in the first 15 min and 2-h of novel exposure but not in the 30-60 min period. When subsequently given food and water for 2-h, Thy1-aSyn mice also had significant lower defecation. Thy1-aSyn mice at a later age (7-8 months) showed a significant reduced fecal output in response to $1-2 \mathrm{~h}$ novel environment exposure taking place either during the light or dark phase without food and subsequently to food exposure. However, at this older age, the cumulative fecal pellet output reduction in the light phase was maintained throughout the $2 \mathrm{~h}$ duration of novel environment, indicative of a progression in the alteration of the defecation response to environmental stimuli. In our previous study, Thy1-aSyn mice aged 12-14 months also displayed prolonged colonic transit time and intracolonic retention of feces postprandially (13). Collectively, these data establish that Thy1-aSyn mice manifest early on a reduction in expulsion of colonic content induced by prokinetic stimuli and such impairment increases with aging compared with littermate WT mice. This Thy1-aSyn mice model may be relevant to colonic motor dysfunction occurring in early stage of PD $(1,8)$.

In the open field test, naïve 4-5 month-old Thy 1-aSyn mice also have lower fecal output than WT mice while displaying features of hyperactivity as shown by increased locomotion, number of center entries and time spent in the middle of the open field compared to WT, 
similar to our previous findings in older mice (14). These data are indicative that reduced defecation during exposure to novel environment is not secondary to reduced locomotion or exploratory behavior in Thy1-aSyn mice consistent with previous studies showing that defecation response is no influenced by locomotor activity levels (29).

The underlying mechanisms of colonic motor alterations may be linked with the overexpression of a-synuclein in colonic myenteric nervous system. First, we showed that the postprandial reduction of defecation is not the consequence of reduced food intake as both genotypes ate a similar amount of food during the $1^{\text {st }}$ hour of refeeding when the difference in fecal output was displayed. In addition, changes in colonic content linked with that of food intake could not be a major component since the transit time from the stomach to distal colon in mice lasts between 140-180 min (30), while the reduced defecation in Thy1-aSyn mice is already significant during the first hour of refeeding after the $2 \mathrm{~h}$ food deprivation. The reduced defecation during refeeding in Thy1-aSyn mice may reflect the alteration of gastro-colic reflex due to overexpression of colonic enteric a-synuclein. Indeed, there was a three-fold increase in a-synuclein immunoreactivity in the distal colon of Thy1-aSyn mice compared to WT mice in the absence of changes in central dopamine, since dopamine and TH levels in the striatum are not reduced in Thy1-aSyn mice until the age of 14 months (14). These data suggest that the impaired defecation response to stimuli in Thy1-aSyn could be related to the accumulation of a-synuclein in colonic myenteric plexuses. An increase of a-synuclein and phospho-a-synuclein are shown in both submucosal and myenteric colonic enteric plexuses of PD patients (31-34). Accumulation of a-synuclein in neurites of colonic myenteric plexus neurons may interrupt neuronal circuitry involved in propulsive motor reflex, although immunohistochemistry did not show proteinase-resistant a-synuclein aggregates. However, it cannot be ruled out that component of the central nervous system also contributes to the impaired defecation responses to novel environment or postprandially. Indeed, aggregates of a-synuclein are present in the brain of the Thy 1-aSyn mice as early as the ages examined (15), as well as in PD patients at sites such as the locus coeruleus (35) and parasympathetic nuclei of the sacral spinal cord (36) known to regulate colonic motility (37-39).

Importantly, the data provide the first evidence suggesting that modified inputs to the colonic enteric cholinergic neurons may occur in a-synuclein overexpressing mice. The colonic myenteric cholinergic neurons in Thy 1 -aSyn mice are surrounded by abundant $a-$ synuclein-positive nerve terminals, while the number of pChAT positive neurons was not changed compared to that of WT mice. Functional studies have established that cholinergic nerves are the main drive to generate giant migrating contractions in the colon leading to defecation in response to a novel environment in mice and rats (18). Although its function is not fully elucidated, $a$-synuclein is a membrane-associated protein present in presynaptic nerve terminals and is a critical regulator of vesicle dynamics at the synapse (40). It is possible that the accumulation of $a$-synuclein in varicose fibers adjacent to myenteric cholinergic neurons impairs the neural input conveyed by a new environment or postprandially. So far little is known on the role of cholinergic neurons in PD constipation. However, indirect evidence supports an impairment of this pathway. Serotonin receptor agonists which stimulate the release of acetylcholine, when tested in PD patients with constipation, enhanced phasic rectal contractions and reduced the volume of post-defecation residuals (41). Another report indicates that a-synuclein over-production in sympathetic nerve fibers of the aorta wall is associated with decreased acetylcholine-induced aorta relaxation in mice (42). Collectively these experimental and clinical studies point to the possibility that disturbed enteric cholinergic neuronal activity may participate in the constipation symptom of PD that will need further investigations. 
We observed few neuronal cell bodies labeled with TH and VIP in the myenteric plexus of the mouse distal colon. This is consistent with previous studies in CD-1 mice showing a few TH-ir neurons in the colonic myenteric plexus (43), and in mouse small intestine where VIP labeling in cell bodies is weak and requires colchicine treatment, unlike the VIP immunostaining in rats (44). Thy 1-aSyn mice aged 8-10 months display neither alteration in TH-ir or VIP-ir nerve fibers, nor changes in nNOS immunoreactive cells/ganglion in distal colonic myenteric system. Likewise, in PD patients the loss of TH-ir neurons in the colon may not be a prominent pathological feature, since their reduction was not significant even in tissue from patients with advanced stage of the disease, while dopamine-ir neurons were significantly decreased (8). Dopamine, VIP and NO may not play a critical role in the colon dysmotility at least in the early stage of PD.

While a-synuclein transgenic mice show increased amounts of a-synuclein in the distal colonic myenteric plexuses and constipation-like responses to a novel environment or postprandially, we found that 4 to 18 months old Thy 1 -aSyn mice, did not display altered gastric emptying of solid meal or non-nutrient semi-liquid compared with their WT littermates. Likewise, in a toxin-induced model of PD, MPTP-treated mice, there was no difference in either liquid or solid gastric emptying (45). Rats with bilateral lesions of substantia nigra by 6-hydroxydopamine (46) or chronic subcutaneous infusion of rotenone (47) show delayed gastric emptying. In the latter model however, a subgroup of treated rats had normal emptying (47) and the delayed gastric emptying might be caused by a direct toxic effect of rotenone on the enteric neurons as rats had severe body weight loss (47). These data demonstrate that gut motor alterations in animal PD models are not identical to the delayed gastric emptying occurring with the progression of $\mathrm{PD}(4,48,49)$, and associated with decreased gastric motility (50). However, it is important to note that in PD patients, gastroparesis is linked with the type of meal, levodopa treatment, and stage of the disease $(48,49,51)$. Indeed, many PD patients are on long term levodopa treatment and gastric emptying measures were performed in patients treated with levodopa $(4,51,52)$, which in itself is known to reduce gastric emptying $(48,53,54)$.

In summary, mice overexpressing human wild type a-synuclein showed reduced defecation in response to environmental stimuli as early as $2.5-3$ months of age, which persists at 8 months while gastric emptying is not modified at ages from 4 to 18 months. Under these conditions, we found that food intake is not altered and locomotor activity is enhanced in mice overexpressing human wild type a-synuclein ruling a role of impaired prandial or exploratory behavior that may impact on defecatory response to a novel environment. The occurrence of functional colonic alterations a year before the loss of striatal dopamine in these animals (14) is compatible with evidence that constipation is one of the most common feature of PD and can develop as a pre-manifest phase of PD (1,3,55). At 8-10 months of age, Thy1-aSyn mice display a three-fold increase in a-synuclein immunoreactivity and in the colonic myenteric system and numerous contacts between $a$-synuclein varicosities and cholinergic neurons, while there were no changes in TH-ir or VIP-ir fibers and pChAT-ir or nNOS-ir neurons compared to WT mice. Accumulation of a-synuclein in neurons innervating colonic pChAT myenteric neurons suggests that altered inputs to cholinergic neurons may contribute to the observed reduction in defecation upon exposure to novelty in Thy1-aSyn mice and postprandially although alterations in brain circuitries involved in the regulation of colonic propulsive motor cannot be ruled out.

\section{Acknowledgments}

The authors thank Dr. G. Ohning (CURE: Digestive Diseases Research Center, Bldg 115, VA Greater Los Angeles Health Care System, Los Angeles) for the generous supply of the VIP antibody CURE ab 7913 and Dr. Hiroshi Kimura (Molecular Neuroscience Research Center, Shiga University of Medical Science, Otsu, Japan) for the generous donation of pChAT antibody, Mrs. Honghui Liang for her technical support, and Ms. Eugenia Hu for her 
review of the manuscript. This work was supported by the (Target validation grant), the Morris K. Udall Parkinson's Disease Research Center of Excellence at UCLA (P50NS38367), Center grant NIHDDK 41301 (Animal Core), RO1 DK 57238 and a VA Career Scientist Award.

\section{References}

1. Pfeiffer RF. Gastrointestinal dysfunction in Parkinson's disease. Parkinsonism Relat Disord. 2011; 17:10-15. [PubMed: 20829091]

2. Savica R, Carlin JM, Grossardt BR, et al. Medical records documentation of constipation preceding Parkinson disease: A case-control study. Neurology. 2009; 73:1752-1758. [PubMed: 19933976]

3. Abbott RD, Petrovitch H, White LR, et al. Frequency of bowel movements and the future risk of Parkinson's disease. Neurology. 2001; 57:456-462. [PubMed: 11502913]

4. Goetze O, Nikodem AB, Wiezcorek J, et al. Predictors of gastric emptying in Parkinson's disease. Neurogastroenterol Motil. 2006; 18:369-375. [PubMed: 16629864]

5. Tofaris GK, Spillantini MG. Physiological and pathological properties of alpha-synuclein. Cell Mol Life Sci. 2007; 64:2194-2201. [PubMed: 17605001]

6. Dickson DW, Braak H, Duda JE, et al. Neuropathological assessment of Parkinson's disease: refining the diagnostic criteria. Lancet Neurol. 2009; 8:1150-1157. [PubMed: 19909913]

7. Wakabayashi K, Takahashi H, Ohama E, Ikuta F. Parkinson's disease: an immunohistochemical study of Lewy body-containing neurons in the enteric nervous system. Acta Neuropathol (Berl). 1990; 79:581-583. [PubMed: 1972853]

8. Singaram C, Ashraf W, Gaumnitz EA, et al. Dopaminergic defect of enteric nervous system in Parkinson's disease patients with chronic constipation. Lancet. 1995; 346:861-864. [PubMed: 7564669]

9. Braak H, de Vos RA, Bohl J, Del Tredici K. Gastric alpha-synuclein immunoreactive inclusions in Meissner's and Auerbach's plexuses in cases staged for Parkinson's disease-related brain pathology. Neurosci Lett. 2006; 396:67-72. [PubMed: 16330147]

10. Kuo YM, Li Z, Jiao Y, et al. Extensive enteric nervous system abnormalities in mice transgenic for artificial chromosomes containing Parkinson disease-associated alpha-synuclein gene mutations precede central nervous system changes. Hum Mol Genet. 2010; 19:1633-1650. [PubMed: 20106867]

11. Vance JM, Ali S, Bradley WG, Singer C, Di Monte DA. Gene-environment interactions in Parkinson's disease and other forms of parkinsonism. Neurotoxicology. 2010; 31:598-602. [PubMed: 20430055]

12. Natale G, Kastsiushenka O, Fulceri F, Ruggieri S, Paparelli A, Fornai F. MPTP-induced parkinsonism extends to a subclass of TH-positive neurons in the gut. Brain Res. 2010; 1355:195206. [PubMed: 20691673]

13. Wang L, Fleming SM, Chesselet MF, Taché Y. Abnormal colonic motility in mice overexpressing human wild-type alpha-synuclein. Neuroreport. 2008; 19:873-876. [PubMed: 18463504]

14. Lam HA, Wu N, Cely I, et al. Elevated tonic extracellular dopamine concentration and altered dopamine modulation of synaptic activity precede dopamine loss in the striatum of mice overexpressing human alpha-synuclein. J Neurosci Res. 2011; 89:1091-1102. [PubMed: 21488084]

15. Chesselet MF, Richter F. Modelling of Parkinson's disease in mice. Lancet Neurol. 2011; 10:1108-1118. [PubMed: 22094131]

16. Million M, Wang L, Stenzel-Poore MP, et al. Enhanced pelvic responses to stressors in female CRF-overexpressing mice. Am J Physiol Regul Integr Comp Physiol. 2007; 292:R1429-R1438. [PubMed: 17194724]

17. Larauche M, Gourcerol G, Million M, Adelson DW, Taché Y. Repeated psychological stressinduced alterations of visceral sensitivity and colonic motor functions in mice: influence of surgery and postoperative single housing on visceromotor responses. Stress. 2010; 13:343-354. [PubMed: 20536336]

18. Gourcerol G, Wang L, Adelson DW, Larauche M, Taché Y, Million M. Cholinergic giant migrating contractions in conscious mouse colon assessed by using a novel noninvasive solid-state 
manometry method: modulation by stressors. Am J Physiol Gastrointest Liver Physiol. 2009; 296:G992-G1002. [PubMed: 19299579]

19. Sang Q, Young HM. The identification and chemical coding of cholinergic neurons in the small and large intestine of the mouse. Anat Rec. 1998; 251:185-199. [PubMed: 9624448]

20. Tooyama I, Kimura H. A protein encoded by an alternative splice variant of choline acetyltransferase mRNA is localized preferentially in peripheral nerve cells and fibers. $\mathrm{J}$ Chem Neuroanat. 2000; 17:217-226. [PubMed: 10697248]

21. Wang L, Martinez V, Kimura H, Taché Y. 5-Hydroxytryptophan activates colonic myenteric neurons and propulsive motor function through 5-HT4 receptors in conscious mice. Am J Physiol Gastrointest Liver Physiol. 2007; 292:G419-G428. [PubMed: 16990446]

22. Yuan PQ, Million M, Wu SV, Rivier J, Taché Y. Peripheral corticotropin releasing factor (CRF) and a novel CRF1 receptor agonist, stressin1-A activate CRF1 receptor expressing cholinergic and nitrergic myenteric neurons selectively in the colon of conscious rats. Neurogastroenterol Motil. 2007; 19:923-936. [PubMed: 17973638]

23. Rockenstein E, Mallory M, Hashimoto M, et al. Differential neuropathological alterations in transgenic mice expressing alpha-synuclein from the platelet-derived growth factor and Thy-1 promoters. J Neurosci Res. 2002; 68:568-578. [PubMed: 12111846]

24. Fleming SM, Salcedo J, Hutson CB, et al. Behavioral effects of dopaminergic agonists in transgenic mice overexpressing human wildtype alpha-synuclein. Neuroscience. 2006; 142:12451253. [PubMed: 16934409]

25. Wang L, Stengel A, Goebel M, et al. Peripheral activation of corticotropin-releasing factor receptor 2 inhibits food intake and alters meal structures in mice. Peptides. 2011; 32:51-59. [PubMed: 20969907]

26. Hickey MA, Gallant K, Gross GG, Levine MS, Chesselet MF. Early behavioral deficits in R6/2 mice suitable for use in preclinical drug testing. Neurobiol Dis. 2005; 20:1-11. [PubMed: 16137562]

27. Martinez V, Wang L, Rivier JE, Vale W, Taché Y. Differential actions of peripheral corticotropinreleasing factor (CRF), urocortin II, and urocortin III on gastric emptying and colonic transit in mice: role of CRF receptor subtypes 1 and 2. J Pharmacol Exp Ther. 2002; 301:611-617. [PubMed: 11961064]

28. Wang L, Martinez V, Rivier JE, Taché Y. Peripheral urocortin inhibits gastric emptying and food intake in mice: differential role of CRF receptor 2. Am J Physiol Regul Integr Comp Physiol. 2001; 281:R1401-R1410. [PubMed: 11641109]

29. Milner LC, Crabbe JC. Three murine anxiety models: results from multiple inbred strain comparisons. Genes Brain Behav. 2008; 7:496-505. [PubMed: 18182070]

30. Carai MA, Colombo G, Gessa GL, Yalamanchili R, Basavarajappa BS, Hungund BL. Investigation on the relationship between cannabinoid CB1 and opioid receptors in gastrointestinal motility in mice. Br J Pharmacol. 2006; 148:1043-1050. [PubMed: 16847440]

31. Shannon KM, Keshavarzian A, Mutlu E, et al. Alpha-synuclein in colonic submucosa in early untreated Parkinson's disease. Mov Disord. 2011

32. Lebouvier T, Neunlist M, Bruley d V, et al. Colonic biopsies to assess the neuropathology of Parkinson's disease and its relationship with symptoms. PLoS ONE. 2010; 5:e12728. [PubMed: 20856865]

33. Beach TG, Adler CH, Sue LI, et al. Multi-organ distribution of phosphorylated alpha-synuclein histopathology in subjects with Lewy body disorders. Acta Neuropathol. 2010; 119:689-702. [PubMed: 20306269]

34. Wakabayashi K, Mori F, Tanji K, Orimo S, Takahashi H. Involvement of the peripheral nervous system in synucleinopathies, tauopathies and other neurodegenerative proteinopathies of the brain. Acta Neuropathol. 2010; 120:1-12. [PubMed: 20532896]

35. Braak E, Sandmann-Keil D, Rub U, et al. alpha-synuclein immunopositive Parkinson's diseaserelated inclusion bodies in lower brain stem nuclei. Acta Neuropathol. 2001; 101:195-201. [PubMed: 11307617] 
36. Bloch A, Probst A, Bissig H, Adams H, Tolnay M. Alpha-synuclein pathology of the spinal and peripheral autonomic nervous system in neurologically unimpaired elderly subjects. Neuropathol Appl Neurobiol. 2006; 32:284-295. [PubMed: 16640647]

37. Monnikes H, Schmidt BG, Tebbe J, Bauer C, Taché Y. Microinfusion of corticotropin releasing factor into the locus coeruleus/subcoeruleus nuclei stimulates colonic motor function in rats. Brain Res. 1994; 644:101-108. [PubMed: 8032938]

38. Bonaz B, Martin L, Beurriand E, Manier M, Hostein J, Feuerstein C. Locus ceruleus modulates migrating myoelectric complex in rats. Am J Physiol. 1992; 262:G1121-G1126. [PubMed: 1352088]

39. Million M, Wang L, Martinez V, Taché Y. Differential Fos expression in the paraventricular nucleus of the hypothalamus, sacral parasympathetic nucleus and colonic motor response to water avoidance stress in Fischer and Lewis rats. Brain Res. 2000; 877:345-353. [PubMed: 10986349]

40. Auluck PK, Caraveo G, Lindquist S. alpha-Synuclein: membrane interactions and toxicity in Parkinson's disease. Annu Rev Cell Dev Biol. 2010; 26:211-233. [PubMed: 20500090]

41. Liu Z, Sakakibara R, Odaka T, et al. Mosapride citrate, a novel 5-HT4 agonist and partial 5-HT3 antagonist, ameliorates constipation in parkinsonian patients. Mov Disord. 2005; 20:680-686. [PubMed: 15719424]

42. Marrachelli VG, Miranda FJ, Alabadi JA, et al. Perivascular nerve fiber alpha-synuclein regulates contractility of mouse aorta: a link to autonomic dysfunction in Parkinson's disease. Neurochem Int. 2010; 56:991-998. [PubMed: 20420875]

43. Li ZS, Pham TD, Tamir H, Chen JJ, Gershon MD. Enteric dopaminergic neurons: definition, developmental lineage, and effects of extrinsic denervation. J Neurosci. 2004; 24:1330-1339. [PubMed: 14960604]

44. Qu ZD, Thacker M, Castelucci P, Bagyanszki M, Epstein ML, Furness JB. Immunohistochemical analysis of neuron types in the mouse small intestine. Cell Tissue Res. 2008; 334:147-161. [PubMed: 18855018]

45. Anderson G, Noorian AR, Taylor G, et al. Loss of enteric dopaminergic neurons and associated changes in colon motility in an MPTP mouse model of Parkinson's disease. Exp Neurol. 2007; 207:4-12. [PubMed: 17586496]

46. Zheng LF, Wang ZY, Li XF, et al. Reduced expression of choline acetyltransferase in vagal motoneurons and gastric motor dysfunction in a 6-OHDA rat model of Parkinson's disease. Brain Res. 2011

47. Greene JG, Noorian AR, Srinivasan S. Delayed gastric emptying and enteric nervous system dysfunction in the rotenone model of Parkinson's disease. Exp Neurol. 2009; 218:154-161. [PubMed: 19409896]

48. Hardoff R, Sula M, Tamir A, et al. Gastric emptying time and gastric motility in patients with Parkinson's disease. Mov Disord. 2001; 16:1041-1047. [PubMed: 11748735]

49. Pfeiffer RF. Gastrointestinal dysfunction in Parkinson's disease. Lancet Neurol. 2003; 2:107-116. [PubMed: 12849267]

50. Soykan I, Lin Z, Bennett JP, McCallum RW. Gastric myoelectrical activity in patients with Parkinson's disease: evidence of a primary gastric abnormality. Dig Dis Sci. 1999; 44:927-931. [PubMed: 10235599]

51. Djaldetti R, Baron J, Ziv I, Melamed E. Gastric emptying in Parkinson's disease: patients with and without response fluctuations. Neurology. 1996; 46:1051-1054. [PubMed: 8780089]

52. Tanaka Y, Kato T, Nishida H, et al. Is there a difference in gastric emptying between Parkinson's disease patients under long-term L-dopa therapy with and without motor fluctuations? An analysis using the (13)C-acetate breath test. J Neurol. 2009; 256:1972-1976. [PubMed: 19575260]

53. Robertson DR, Renwick AG, Macklin B, et al. The influence of levodopa on gastric emptying in healthy elderly volunteers. Eur J Clin Pharmacol. 1992; 42:409-412. [PubMed: 1516606]

54. Heetun ZS, Quigley EM. Gastroparesis and Parkinson's disease: A systematic review. Parkinsonism Relat Disord. 2011

55. Korczyn AD, Gurevich T. Parkinson's disease: before the motor symptoms and beyond. J Neurol Sci. 2010; 289:2-6. [PubMed: 19801155] 

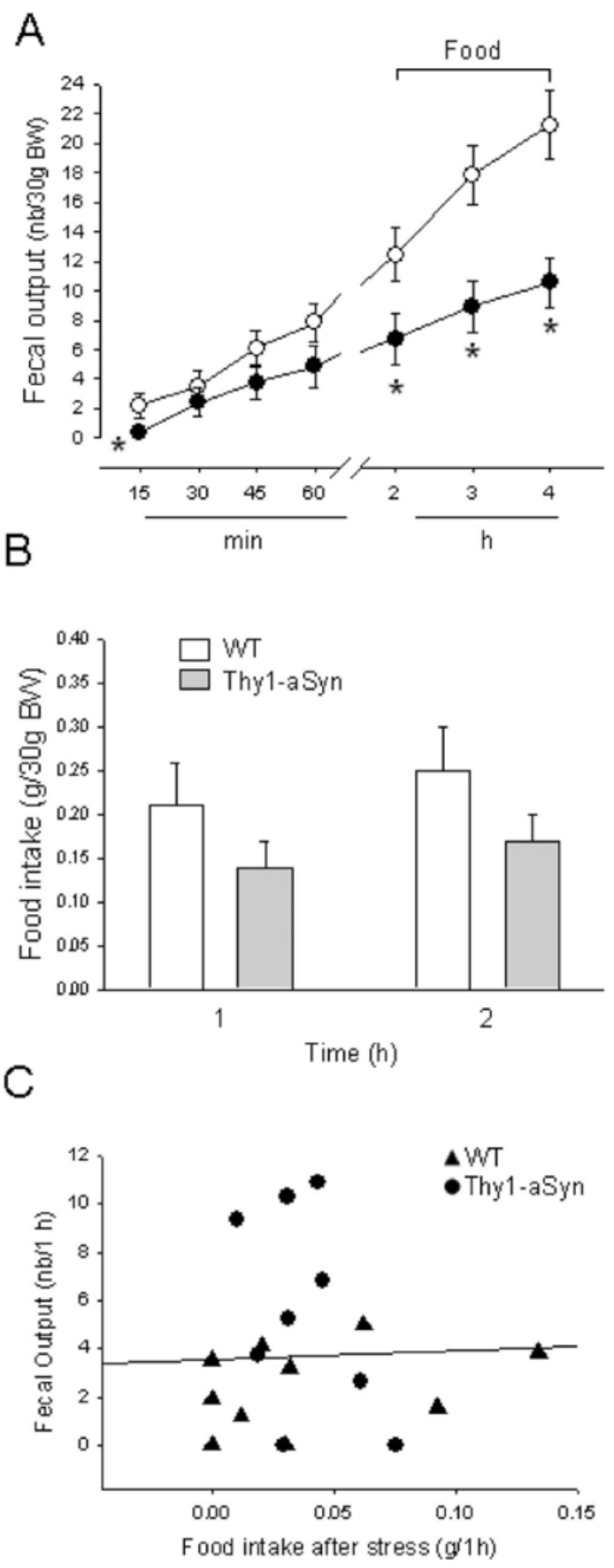

Fig. 1.

A. Reduced defecation in 2.5-3 months old Thy 1-aSyn mice compared to WT littermates in response to novel environment exposure in the light phase. Male Thy1-aSyn mice $(\mathrm{n}=11)$ and WT littermates $(n=9)$ were placed singly in a new cage for $2 \mathrm{~h}$ without food and water and with food and water for the subsequent $2 \mathrm{~h}$ period; defecation and food intake were monitored. B. Cumulative food intake. C. Correlation between fecal output and food intake during the $2 \mathrm{~h}$ refeeding period. Data are expressed as mean $\pm \mathrm{SEM}, *: p<0.05$ compared with WT; Student's t-test. 

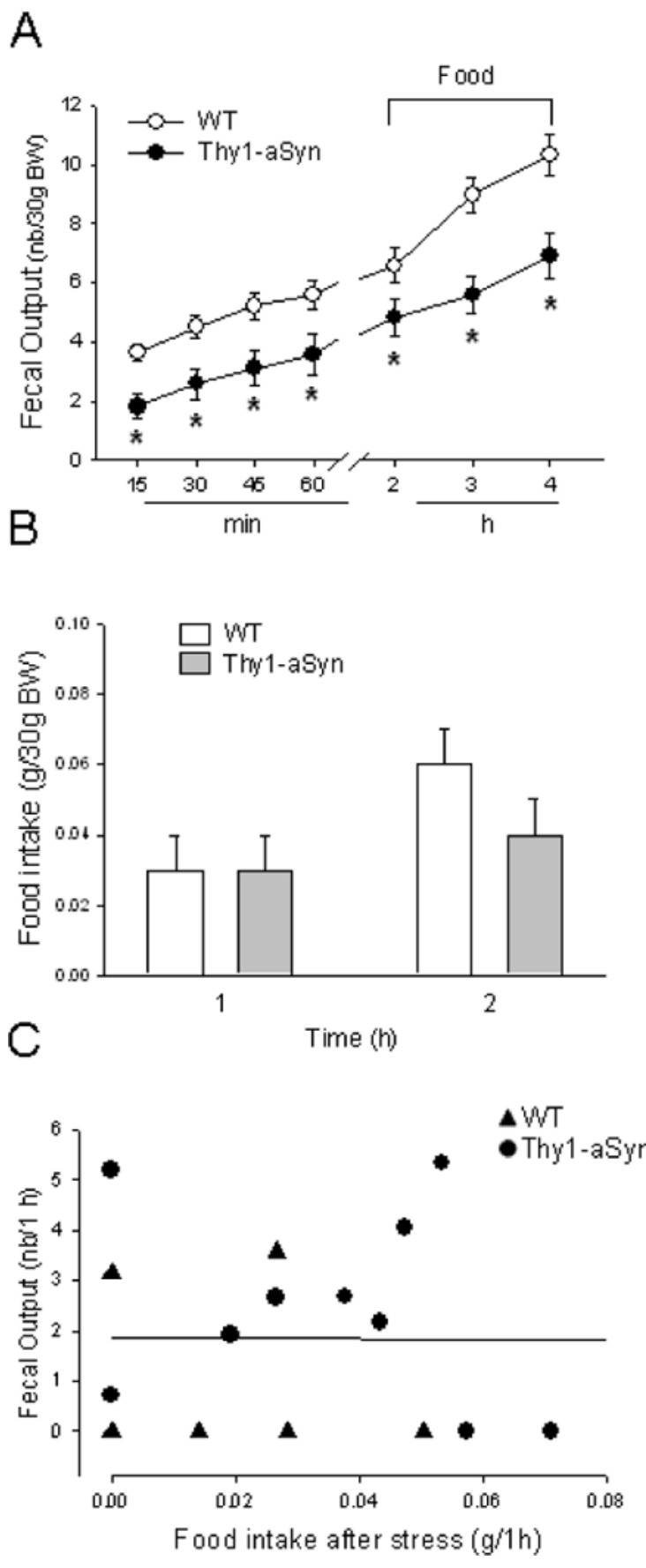

Fig. 2.

A. Reduced defecation in 7-8 months old Thy1-aSyn mice compared to WT littermates in response to novel environment exposure in the light phase. Male Thy 1 -aSyn mice $(n=5)$ and WT littermates $(n=10)$ were placed singly in a new cage for $2 \mathrm{~h}$ without food and water and the subsequent $4-\mathrm{h}$ with food and water. B. Cumulative food intake. C. Correlation between fecal output and food intake during the $2 \mathrm{~h}$ refeeding period. Data are expressed as mean \pm SEM, * $: p<0.05$ compared with WT; Student's t-test. 
A

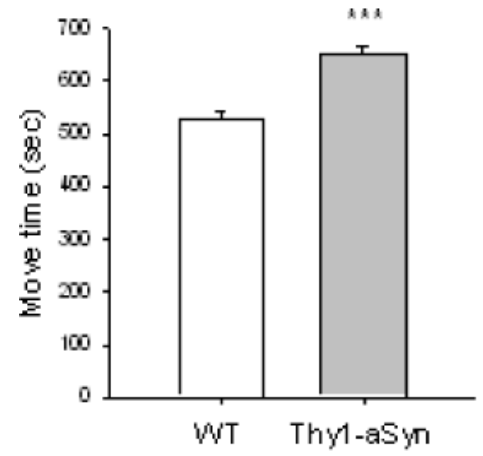

D

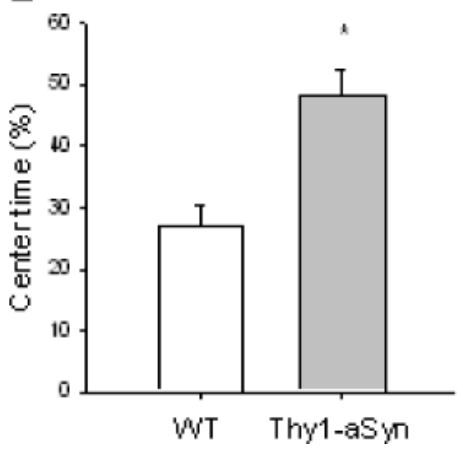

B

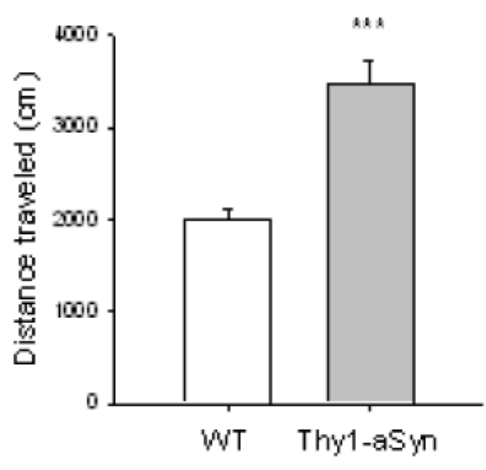

E

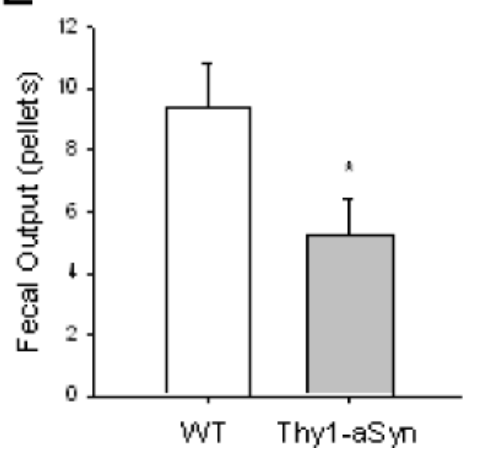

C

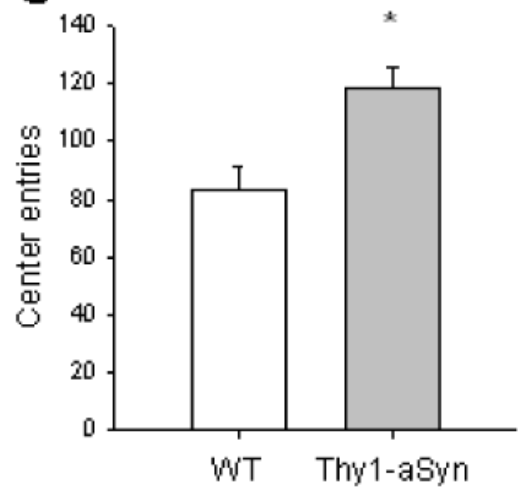

Fig. 3.

Open field activity of 4-5 months old male Thy1-aSyn $(\mathrm{n}=11)$ and WT mice $(\mathrm{n}=10)$ monitored for $15 \mathrm{~min}$. A. Tine in motion. B. Distance traveled. C. Center entries. D. Center time. E. Fecal pellet output. Data are expressed as mean \pm SEM, *: $p<0.05$ compared with WT; Student's t-test. 

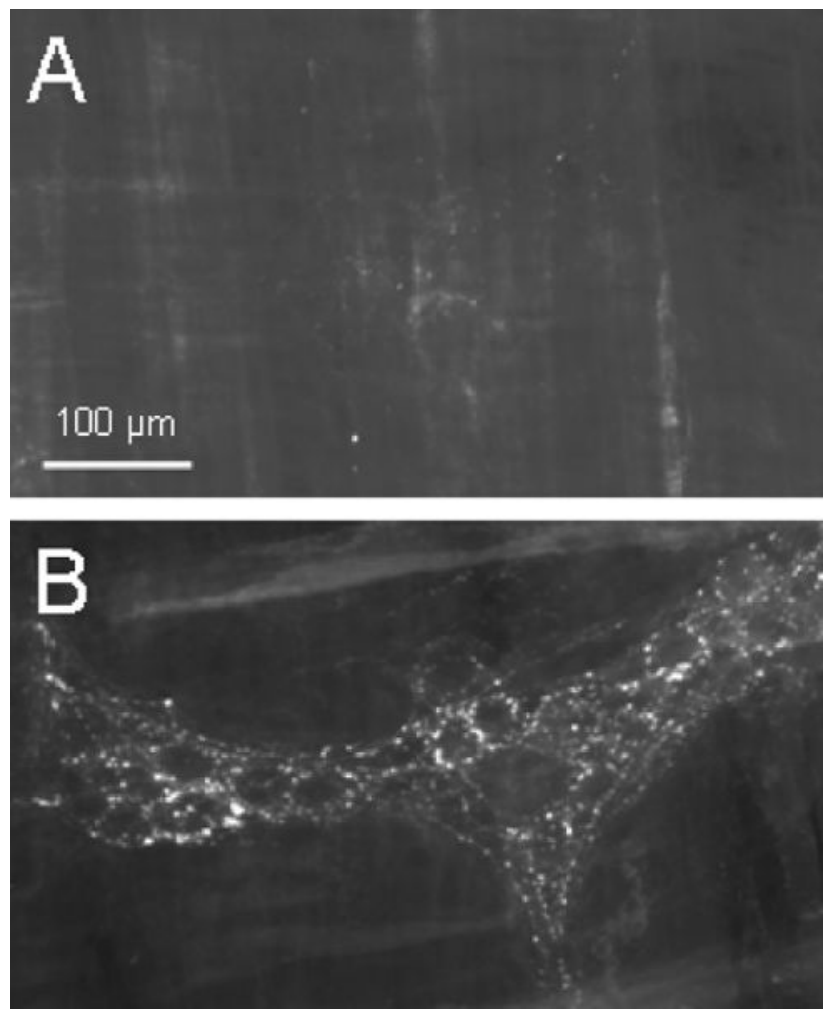

Fig. 4.

Representative photomicrographs showing immunoreactivity of a-synuclein in the distal colon myenteric plexus of WT (A) and Thy1-aSyn (B) 8-10 months old mice. Scale = 100 $\mu \mathrm{m}$ for both panels. 

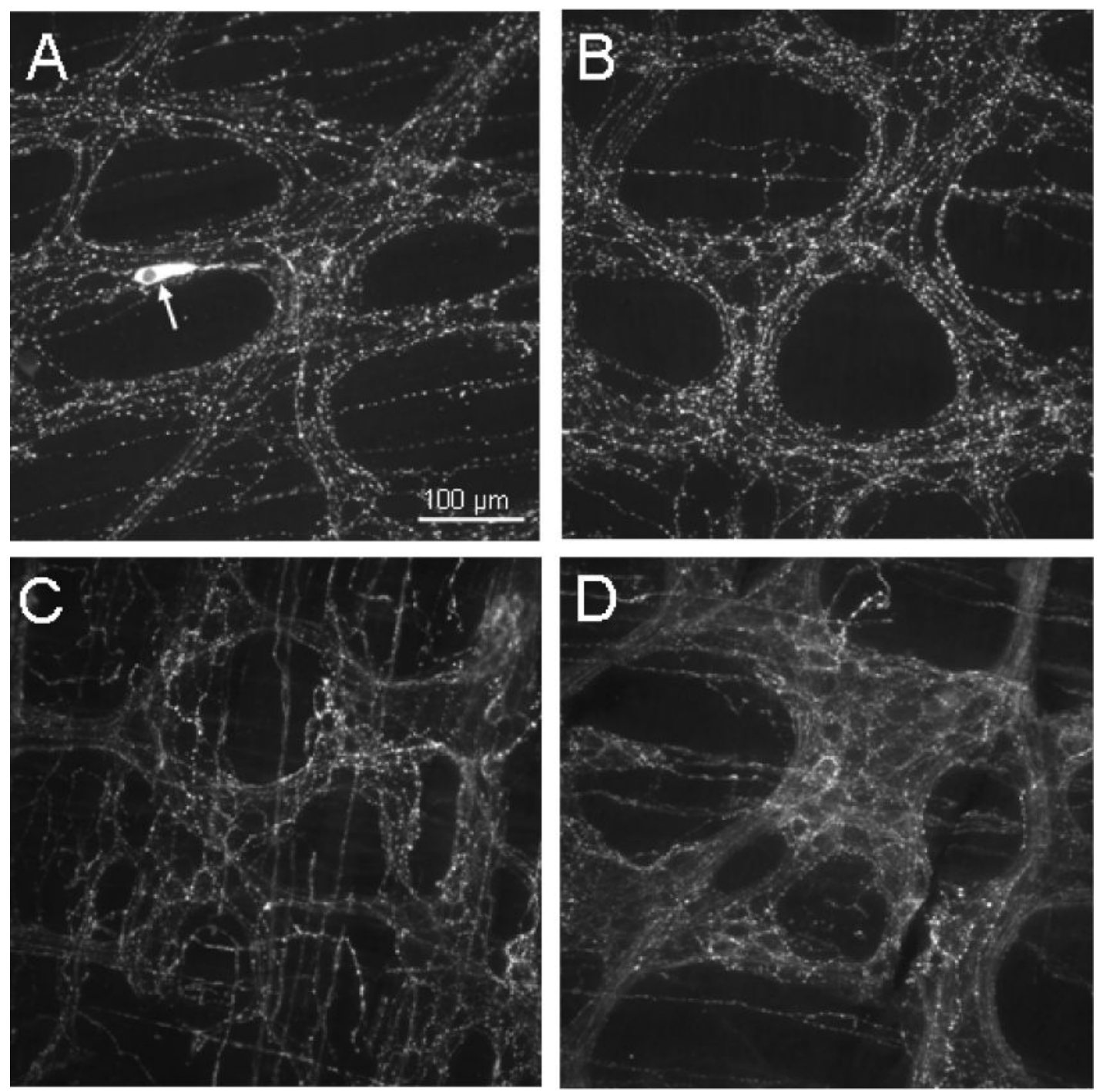

Fig. 5.

Representative photomicrographs of myenteric plexus in the distal colon with immunoreactivity of tyrosine hydroxylase (A, B) and vasoactive intestinal peptide (C, D) in WT (A, C) and Thy 1-aSyn (B, D) 8-10 months old mice. Immunoreactivity is located prominently in nerve fibers. The arrow in A shows a TH-ir neuron. Scale $=100 \mu \mathrm{m}$ for all panels. 

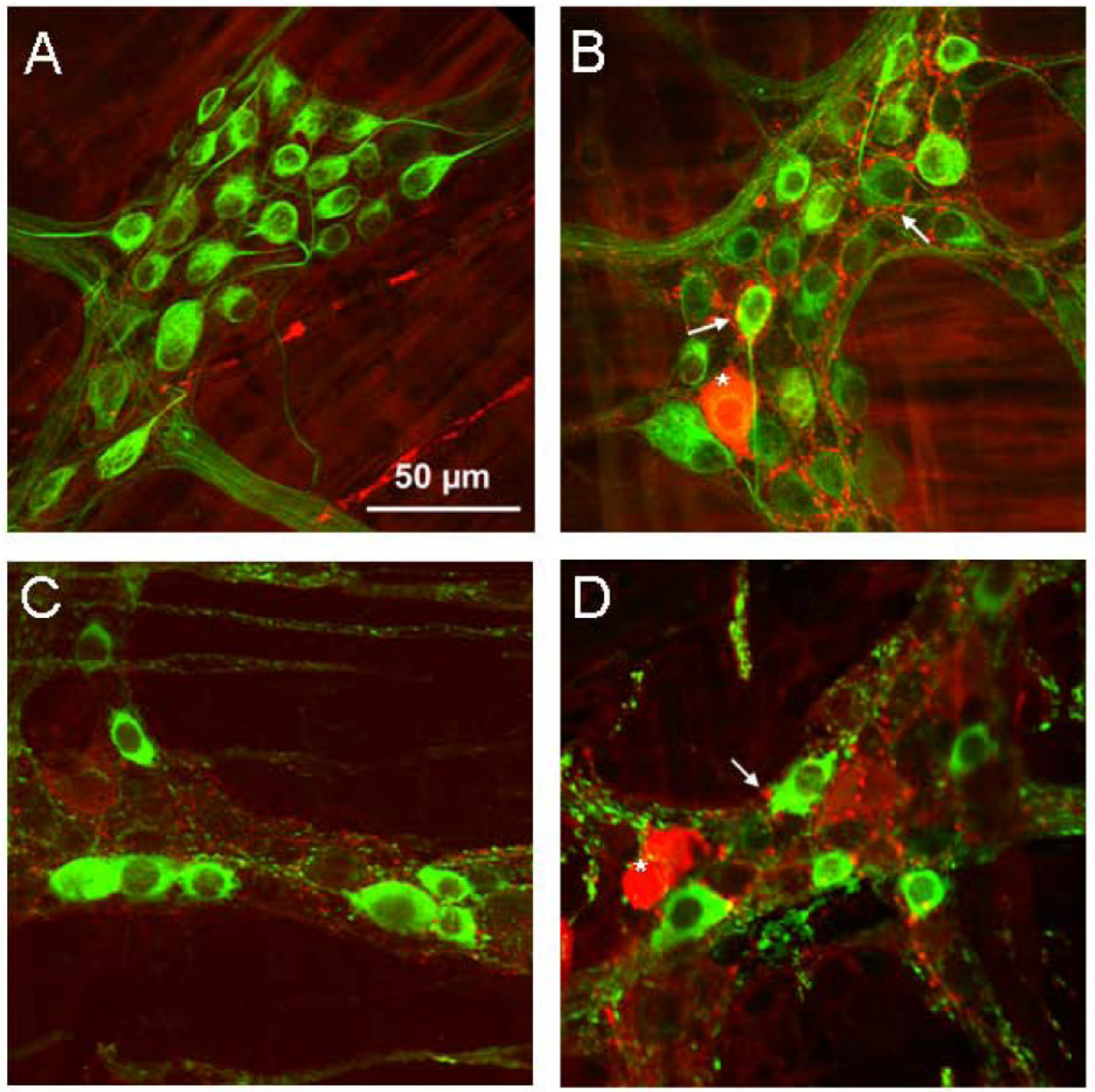

Fig. 6.

Representative confocal microphotographs showing the double labeling of immunoreactivity of a-synuclein (red) with peripheral choline acetyl transferase (pChAT, green) (A, B), or with neuronal nitric oxide synthase (nNOS, green) (C, D) in myenteric ganglia of distal colon in WT mice (A, C) and Thy1-aSyn mice (B, D). Arrows indicate aSyn-ir varicosities adjacent to pChAT-ir (B) and nNOS-ir neurons (D). Stars indicate a-synuclein-ir neurons. Scale $=50 \mu \mathrm{m}$ for all panels. 


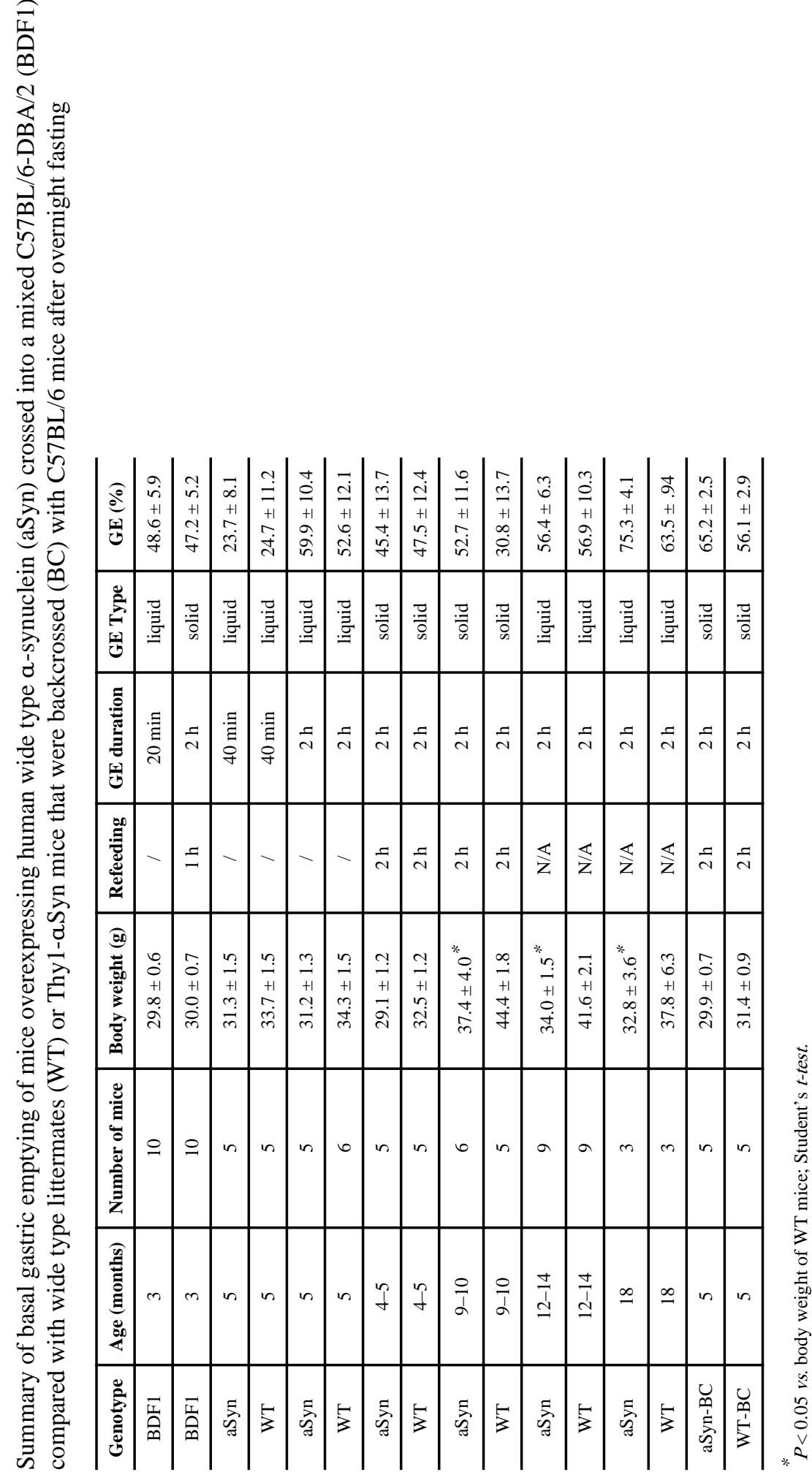


Table 2

Quantitative analysis of a-synuclein, TH, VIP, pChAT and nNOS immunoreactivity in the distal colonic enteric plexuses of Thy1-aSyn mice and WT littermates. $\mathrm{N}=3-6, *: p<0.05$ compared with WT, Student's $t$ test.

\begin{tabular}{|l|c|c|c|}
\hline & WT & Thy1-aSyn & Units \\
\hline a-Synuclein-ir varicosities & $82.9 \pm 30.1$ & $254.0 \pm 39.7^{*}$ & Counts/ganglion \\
\hline TH-ir fibers & $364.6 \pm 10.1$ & $365.5 \pm 10.6$ & Density/ $\mu \mathrm{m}^{2}$ \\
\hline VIP-ir fibers & $322.8 .4 \pm 17.7$ & $353.4 \pm 14.4$ & Density/ $\mu \mathrm{m}^{2}$ \\
\hline pChAT-ir neurons & $13.9 \pm 1.0$ & $14.1 \pm 0.5$ & Cells/ganglion \\
\hline nNOS-ir neurons & $6.4 \pm 0.3$ & $6.7 \pm 0.4$ & Cells/ganglion \\
\hline
\end{tabular}

Density: integrated density obtained by image analysis using Image $\mathbf{J}$ 